\title{
ESTRUTURA FUNDIÁRIA E CONSERVAÇÃO DE FLORESTAS EM PROPRIEDADES RURAIS DO CIRCUITO DAS FRUTAS/SP: UMA ANÁLISE DOS IMPACTOS DA LEI 12.651/2012 NA CONFORMAÇÃO DE RESERVAS LEGAIS E COTAS DE RESERVA AMBIENTAL
}

\author{
Felipe Rosafa Gavioli \\ Companhia Ambiental do Estado de São Paulo, Jundiaí, SP, Brasil \\ gavioli.f@gmail.com
}

Raquel Carnivalle Silva Melillo Centro Universitário Padre Anchieta, Jundiaí, SP, Brasil raquel.melillo@anchieta.br

Cristiane Ronchi de Oliveira

Centro Universitário Padre Anchieta, Jundiaí, SP, Brasil cristianeronchi@hotmail.com

\begin{abstract}
RESUMO
Com a Lei 12.651/2012, a estrutura fundiária passou a condicionar as ações de proteção florestal, variáveis conforme o tamanho dos imóveis rurais. Este estudo analisou, a partir de geoprocessamento, a estrutura fundiária e a cobertura florestal em imóveis rurais do Circuito das Frutas/SP, com vistas a avaliar os impactos da Lei 12.651/2012 na instituição de Reservas Legais (RLs) e Cotas de Reserva Ambiental (CRAs) no território. No Circuito das Frutas há 5.784 propriedades cadastradas no Cadastro Ambiental Rural, com área de 125 mil hectares, das quais $91,60 \%$ são pequenas propriedades. A cobertura florestal incidente nas propriedades soma 32,5 mil hectares. $O$ artigo 67 da lei florestal reduz em 3,79 mil hectares (ou 68,22\%) as RLs das pequenas propriedades, e a demanda potencial por CRAs é de 3,45 mil hectares, sendo que há 8,14 mil hectares de florestas que poderiam compensar este déficit garantindo adicionalidade. Conclui-se que o impacto do artigo 67 da lei florestal no território é relevante, afetando a conservação da biodiversidade. De outro lado, há potencial para proteger florestas passíveis de supressão legal pela instituição de CRAs, sendo que a regulamentação da lei florestal deve buscar critérios ecológicos e de adicionalidade para viabilizar estes arranjos de compensação.
\end{abstract}

Palavras-chave: Código florestal. Regularização florestal. Cadastro Ambiental Rural.

\section{LAND STRUCTURE AND CONSERVATION OF FORESTS IN RURAL PROPERTIES OF THE FRUIT CIRCUIT/SP: AN ANALYSIS OF THE IMPACTS OF LAW 12.651/2012 ON CONFORMING LEGAL RESERVES AND ENVIRONMENTAL RESERVE QUOTAS.}

\begin{abstract}
With the publication of the Law 12.651/2012, the land structure began to condition forest protection, which vary according to the size of rural properties. This study analyzed, from geoprocessing, the land structure and forest cover in rural properties of the Fruit Circuit/SP, in order to evaluate the impacts of forest law on the institution of Legal Reserves (RLs) and Environmental Reserve Quotas (CRAs) in the territory. In the Fruit Circuit there are 5.784 properties registered in the Rural Environmental Registry, with an area of 125 thousand hectares, of which $91.60 \%$ are small properties. The forest cover on the properties amounts to 32.5 thousand hectares. Article 67 of the forest law reduces by 3.79 thousand hectares (or $68.22 \%$ ) the RLs of small properties, and the potential demand for CRAs is around 3.45 thousand hectares, with 8.14 thousand hectares of forests that could compensate this deficit by ensuring additionality. It is concluded that the impact of article 67 on the territory is relevant, affecting the conservation of biodiversity. On the other hand, there is potential to protect forests exposed to legal suppression by the establishment of CRAs, and forest law regulation must seek additional and ecological criteria to make these compensation arrangements viable.
\end{abstract}

Keywords: Forest Code. Forest regularization. Rural Environmental Register. 


\section{INTRODUÇÃO}

Diversos estudos têm apontado para a importância da manutenção e da restauração de fragmentos de florestas nativas em paisagens da matriz agrícola, como estratégia central para a promoção de serviços ecossistêmicos relevantes nestes ambientes antropizados (BURKHARD et al., 2009; BRANCALION et al., 2013; BARRAL et al., 2015; SCHMIDT et al., 2019).

Tais serviços incluem a conservação da biodiversidade, a regulação climática, o provisionamento de água, o controle da erosão, a estocagem de carbono através da biomassa florestal, o aumento das populações de insetos polinizadores, dentre outros benefícios associados às florestas nativas em paisagens agrícolas, que contribuem inclusive para o incremento das funções produtivas dos agroecossistemas, em especial nas regiões tropicais (ALEXANDER et al., 2016; REED et al., 2017).

A construção de paisagens agrícolas amigáveis para a biodiversidade e capazes de prover serviços ecossistêmicos, necessariamente passa pela regulação do uso do solo nas propriedades privadas rurais, que abrigam cerca de $53 \%$ da vegetação nativa existente nos distintos biomas brasileiros (SOARESFILHO et al., 2014).

Neste contexto, a legislação florestal brasileira (LFB), materializada na Lei Federal ํㅜ 12.651/2012, com alterações dadas pela Lei 12.727/2012 e regulamentada pelo Decreto 7.830/2012, adquire enorme relevância, já que é a principal legislação para a proteção dos recursos florestais em propriedades privadas no país (AGUIAR et al., 2017). Tal proteção se concretiza através de duas categorias de áreas especialmente protegidas, definidas na legislação: as Áreas de Preservação Permanente (APPs) e a Reserva Legal (RL).

As APPs são áreas de ocupação restrita, aplicáveis tanto em propriedades urbanas quanto em imóveis rurais, e instituídas em faixa variável ao longo dos rios e córregos, no entorno de nascentes, em áreas de elevada declividade, dentre outras áreas frágeis do ponto de vista ambiental ou geotécnico (BRASIL, 2012).

A RL é definida como uma área a ser mantida com cobertura de vegetação nativa no interior das propriedades rurais, em percentual que varia de $20 \%$ a $80 \%$ da área total, a depender do bioma no qual o imóvel rural se localiza, e que tem a função de reabilitar processos ecológicos, conservar a biodiversidade e garantir o uso econômico sustentável dos recursos naturais nos territórios rurais (BRASIL, 2012).

Ambos os dispositivos já eram previstos na lei florestal de 1965 - Lei Federal oㅜ 4.771, que foi alterada e revogada pela Lei 12.651, promulgada em maio de 2012. No entanto, o diploma legal vigente se diferencia em grande medida de seu antecessor de 1965 ao estabelecer disposições transitórias (capítulo XIII da LFB), que possibilitam a adequação ambiental dos imóveis rurais em determinadas situações, com a flexibilização na proteção das APPs e na instituição da RL (BRANCALION et al., 2016).

Esta flexibilização ocorre, no caso das APPs, mediante a possibilidade de reconhecimento e de manutenção de áreas de uso consolidado em áreas protegidas a título de Preservação Permanente, ou seja, a lei florestal brasileira possibilita a regularização e continuidade das atividades agrossilvipastoris, de turismo rural ou de ecoturismo, estabelecidas em APP, em data anterior a 22/07/2008, sendo que a regularização deste uso consolidado é condicionada à restauração florestal de parte da APP remanescente, em faixas variáveis em acordo com o tamanho da propriedade expresso em módulos fiscais, conforme dispõe o art. 61-A do diploma legal (BRASIL, 2012).

No que se refere à flexibilização na instituição de RLs, a disposição transitória indica, no artigo 67 da LFB, que as pequenas propriedades rurais, com área de até quatro módulos fiscais, podem constituir a RL com os fragmentos florestais existentes no imóvel até 22/07/2008, mesmo que tais fragmentos incidam em

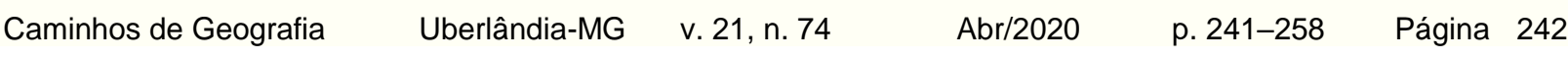


percentuais inferiores ao mínimo estabelecido para conformar a $\mathrm{RL}$, que é de $20 \%$ da área total da propriedade rural no caso do bioma Mata Atlântica, conforme art. 12 da própria lei. Cumpre indicar que na aplicação desta disposição, há a condicionante de vedação de novas supressões de vegetação nativa na pequena propriedade beneficiada. Ademais, a Lei 12.651/2012 possibilitou também a inclusão das APPs no computo de $R L$ das propriedades, implicando em sobreposição destas áreas em determinados casos, conforme art. 15 do diploma legal (BRASIL, 2012).

Desta forma, e a partir do previsto no art. 67 da LFB, abre-se a possibilidade de regularizar a $R L$ das pequenas propriedades rurais em percentuais inferiores ao estabelecido nas disposições gerais da LFB, ou no limite isentar a pequena propriedade da instituição de $R L$, sem necessidade de restauração florestal para o imóvel que até a data limite de 22/07/2008 não possuía qualquer remanescente de vegetação nativa.

Para Mariga e Ruscheinsky (2017), o disposto no art. 67 é na prática uma anistia aos proprietários rurais que suprimiram vegetação nativa de modo irregular em período anterior a julho de 2008, e indica um menosprezo às práticas de sustentabilidade no desenvolvimento agrícola nacional.

Aguiar et al. (2017) corroboram este entendimento, e indicam que a regularização dos usos consolidados em APP e em RL pela aplicação dos art.s 61-A e 67 acabam por punir, indiretamente, os proprietários rurais que estavam em acordo com as restrições do código florestal de 1965. Na mesma linha,Milaré e Machado (2012), apontam que a LFB regularizou situações antes consideradas como ilícitos ambientais, com desconsideração da legislação prévia que tratava o assunto. Segundo Santiago et al. (2017), a Lei 12.651/2012, ao flexibilizar a restauração da $R L$ para as pequenas propriedades e também ao permitir a sobreposição da RL às APPs conforme art. 15 da LFB, rompe com uma tendência histórica de construção da $R L$ como instrumento de conservação ambiental, retirando as condições necessárias para sua eficácia.

Desta forma, a flexibilização na restauração florestal das APPs e RLs, contidas nos artigos 61-A e 67 da LFB, e as possibilidades de sobreposição destas duas categorias de áreas especialmente protegidas conforme art. 15 da LFB, fragilizam os instrumentos de proteção estabelecidos na legislação, e podem trazer riscos reais de impacto relevante na conservação florestal de biomas que já apresentam algum grau de degradação, como é o caso específico da Mata Atlântica, um dos cinco hotspots de biodiversidade mais relevantes em ocorrência de espécies endêmicas do planeta (MYERS et al., 2000), e também um dos mais devastados e ameaçados (DEAN, 2004), com estimativas de remanescentes de vegetação nativa que variam de 12,4\% (FUNDAÇÃO SOS MATA ATLÂNTICA, 2018) a 28\% (REZENDE et al, 2018) de sua cobertura florestal original.

O presente trabalho se insere neste contexto de fragilização dos instrumentos de proteção florestal em áreas privadas, dado pela implementação das disposições transitórias da legislação florestal brasileira, e busca avaliar o panorama da cobertura florestal sobre os imóveis rurais no território do Circuito das Frutas (CF), no interior do estado de São Paulo, com especial ênfase sobre as possibilidades de proteção desta cobertura florestal pelo instrumento da RL, o que envolve o impacto da aplicação do art. 67 do diploma legal neste território, bem como a oferta e demanda potencial por Cotas de Reserva Ambiental (CRAs) na área de estudo.

O estudo se justifica pela escassez de estudos concretos acerca do impacto das disposições da LFB, cuja aplicação representa um potencial de acarretar em importantes riscos de redução das áreas protegidas nas propriedades rurais, afetando negativamente a conservação dos remanescentes florestais e da biodiversidade nas paisagens de matriz agropecuária, em especial nos territórios marcados por uma estrutura fundiária baseada nas pequenas propriedades, como é o caso específico do CF. 


\section{RESERVA LEGAL, CADASTRO AMBIENTAL RURAL E COTAS DE RESERVA AMBIENTAL - NOVAS ABORDAGENS ESTABELECIDAS PELA LEI FLORESTAL BRASILEIRA}

Ainda são escassos os estudos que trataram do impacto real e efetivo do disposto no art. 67 da LFB. Wollmann e Bastos (2015) analisaram a conformação de RLs no marco da Lei 12.651/2012 em propriedades rurais na região sul do município de Porto Alegre/RS, constatando que um quarto das pequenas propriedades estudadas apresentavam fragmentos florestais em percentual inferior a $20 \%$. Segundo os autores, $1,4 \%$ da área destas pequenas propriedades, que deveria ser destinada como $R L$ no marco do código florestal de 1965, ficou isenta de recuperação florestal a partir da aplicação do art. 67 (WOLLMANN e BASTOS, 2015).

Analisando o impacto do art. 67 da LFB em imóveis rurais na região de Lavras em Minas Gerais, Soares et al. (2019) verificaram uma redução de 7\% da área de RL devida para os imóveis rurais amostrados.

No contexto nacional, Guidotti et al. (2017) estimaram a redução da RL pela aplicação do art. 67 no bioma Mata Atlântica em 4,9 milhões de hectares, ou $25 \%$ da $R L$ que seria devida sem a existência do dispositivo de flexibilização, que foi calculada em 19,6 milhões de hectares no bioma, considerando o percentual de $20 \%$ de cobertura florestal em todos os imóveis rurais. No estado de São Paulo, Freitas et al. (2016) estimam redução nas áreas de RL da ordem de 720 mil hectares pela aplicação do art. 67 da LFB.

Em um estudo exploratório realizado no estado de São Paulo, Gavioli (2017) verificou que a aplicação do art. 67 da LFB pode acarretar em impacto potencial de perda de 996 mil hectares de RLs nas pequenas propriedades paulistas, ao passo que a $R \mathrm{~L}$ obrigatória a ser instituída em médias e grandes propriedades seria da ordem de 3,5 milhões de hectares. Na região administrativa de Campinas, na qual os municípios do CF estão inseridos, a aplicação do art. 67 pode resultar em perda potencial de 123 mil hectares de RL para as pequenas propriedades rurais (GAVIOLI, 2017).

Tanto a redução da $R L$ para as pequenas propriedades conforme reza o art. 67 da lei, quanto a redução da faixa obrigatória de recomposição de APP em função do reconhecimento de usos rurais consolidados conforme estabelece o art. 61-A da LFB, são dispositivos aplicáveis no âmbito do Programa de Regularização Ambiental (PRA), que por sua vez é estruturado sobre a base de dados do Cadastro Ambiental Rural (CAR).

Registro eletrônico obrigatório para todas as propriedades rurais, o CAR é uma das principais inovações da Lei 12.651/2012, e constitui uma base de dados que permite radiografar a situação ambiental, florestal e fundiária de um determinado território (BRANCALION et al., 2016).

Tal registro é realizado pelo proprietário ou possuidor do imóvel rural, sobre imagens de satélite georreferenciadas que abrangem a totalidade do território nacional, disponíveis na plataforma eletrônica do Sistema Nacional de Cadastro Ambiental Rural (SICAR), sob a gestão do Serviço Florestal Brasileiro. O cadastramento envolve a delimitação do imóvel rural, a delimitação de fragmentos florestais remanescentes, a indicação das APPs e das áreas de $\mathrm{RL}$, bem como a indicação de uso rural consolidado em APPs, áreas de uso restrito e de servidão administrativa (BRASIL, 2014).

Concebido como instrumento de gestão florestal e como repositório de dados para subsidiar a aplicação da LFB, o CAR possibilita o diagnóstico de ativos e de passivos ambientais em escala territorial, permitindo variadas aplicações em planejamento e gestão ambiental (LAUDARES et al., 2014), com possibilidades ainda pouco exploradas de subsidiar análises de dinâmicas sociais, econômicas, políticas e fundiárias dos territórios rurais (JUNG et al., 2017). 
O registro dos imóveis no CAR é elemento central da arquitetura de gestão florestal implementada pela Lei 12.651/2012, já que é a partir das informações ambientais declaradas no CAR que o proprietário rural poderá aderir ao PRA, momento no qual é possível efetivar a regularização ambiental da propriedade.

Nesta regularização, é facultado ao proprietário rural requerer a aplicação das disposições transitórias da LFB, que envolvem a recomposição florestal das APPs em faixas variáveis conforme o tamanho do imóvel quando há uso agrossilvipastoril reconhecido nestas áreas protegidas, bem como a instituição de RL reduzida à fração de vegetação nativa existente nas pequenas propriedades, sem necessidade de restauração florestal na hipótese da vegetação nativa existente conformar percentual inferior ao exigível no art. 12 da LFB.

No caso das médias e grandes propriedades, a regularização das áreas de $R L$ segue a disposição geral contida na LFB, que estabelece necessidade de instituição de RL em área equivalente a no mínimo $20 \%$ da área dos médios e grandes imóveis, inseridos no bioma Mata Atlântica, inclusive com a possibilidade de computar a APP em sobreposição a RL. Na hipótese de o médio ou grande imóvel rural apresentar cobertura florestal inferior a $20 \%$ da área total, o proprietário deverá promover a restauração florestal de áreas degradadas, havendo ainda a possibilidade da compensação da área de RL faltante mediante aquisição de CRAs.

Prevista no art. 44 da LFB, a CRA é um mecanismo de mercado que possibilita que o déficit de RL de uma propriedade rural seja compensado nos maciços florestais excedentes ao percentual mínimo de RL de um outro imóvel, desde que alocados no mesmo bioma e prioritariamente no mesmo estado da federação. A CRA também pode ser instituída sobre áreas florestadas protegidas sob a forma de Reserva Particular do Patrimônio Natural, que é uma categoria de Unidade de Conservação (UC) de proteção integral estabelecida em imóveis privados, ou ainda instituída em imóveis localizados em demais categorias de UCs de domínio público, ainda não desapropriadas. Excepcionalmente para as pequenas propriedades e assentamentos de reforma agrária, a CRA pode ser alocada sobre a vegetação nativa que já se encontra protegida sob a forma de RL (BRASIL, 2012).

Para Aguiar et al. (2017), o mecanismo das CRAs pode ser utilizado para regularização dos imóveis localizados em zonas vocacionadas para a agricultura, nas quais o deslocamento da produção pela restauração florestal pode se apresentar inviável, considerando o custo de oportunidade das terras. Os autores ainda apontam que o mecanismo da CRA possibilita uma valorização das áreas florestadas excedentes ao percentual de $\mathrm{RL}$, que poderiam ser legalmente suprimidas, acarretando em adicionalidade de proteção florestal (AGUIAR et al., 2017).

A indicação das áreas que conformarão CRAs é realizada pelo proprietário no âmbito do CAR, sendo que cada cota equivale a um hectare recoberto por vegetação nativa ou em processo de recuperação florestal, desde que excedente ao montante mínimo de $R L$ a ser instituído em favor do próprio imóvel. Depois de delimitadas no CAR, as CRAs são emitidas pelo órgão ambiental mediante requisição do proprietário, ao que ficam disponíveis para cessão ou aquisição por terceiros. As CRAs podem também ser alocadas sobre fragmentos florestais incidentes em APP (BRASIL, 2012).

Uma vez que as pequenas propriedades rurais se beneficiam do art. 67 na regularização de suas RLs, têm-se que as CRAs serão adquiridas somente pelas médias e grandes propriedades. Sem embargo, qualquer imóvel rural, inclusive aqueles com área inferior a quatro módulos fiscais, podem constituir CRAs para cessão ou venda, sendo que neste último universo as CRAs podem ser alocadas de modo sobreposto à área de RLRL obrigatória (PEREIRA, 2017).

Estima-se que a oferta de áreas para conformar CRAs no território nacional gire em torno de 156 milhões de hectares, ao passo que a demanda potencial para compensação de $R L$ por este instrumento seja da 
ordem de 13,1 milhões de hectares, o que pode inviabilizar a criação de um mercado eficiente devido à desproporcionalidade entre oferta e demanda (FREITAS et al., 2016).

\section{METODOLOGIA}

O CF é um aglomerado frutícola instituído pelo governo paulista através do Decreto Estadual 47.180/2002, sendo atualmente composto pelos municípios de Atibaia, Indaiatuba, Itatiba, Itupeva, Jarinu, Jundiaí, Louveira, Morungaba, Valinhos e Vinhedos (OTANI et al., 2012). Estes dez municípios, localizados na região administrativa de Campinas e próximos a região metropolitana de São Paulo, apresentam em comum uma ruralidade formada pela chegada de imigrantes, em especial italianos e japoneses, que adquiriram parcelas de terra e iniciaram o cultivo de frutas de clima temperado e sub-tropical como uvas, pêssego, caqui, morango e goiaba na região, a partir do início do século XX (QUEIROGA et al., 2018). A localização do CF em relação ao território paulista é indicada no mapa da Figura 1.

Figura 1 - Circuito das Frutas paulista: localização e municípios.

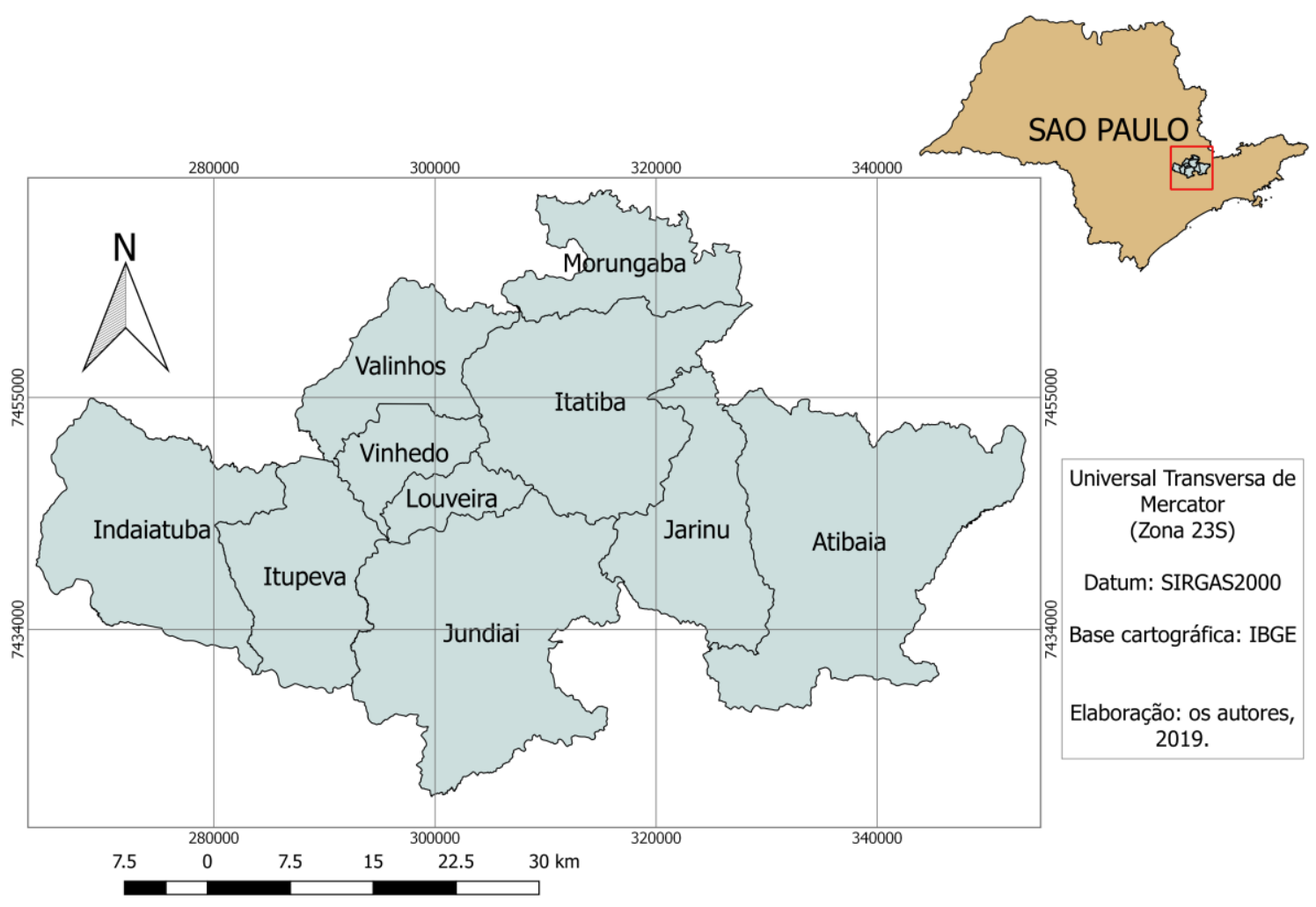

Fonte - Os autores, 2019.

Historicamente, no CF há uma presença marcante da agricultura familiar, que se caracteriza pela fruticultura e pela valorização das tradições culturais herdadas dos primeiros imigrantes (SOUZAESQUERDO e BERGAMASCO, 2014). Estes aspectos, associados à proximidade da região com grandes centros urbanos, favorecem o desenvolvimento de atividades de agroturismo e ecoturismo, que se tornam cada vez mais importantes na economia rural local (PEREIRA e MOLINA, 2007). Estas atividades, por sua vez, podem se beneficiar dos ativos próprios de uma ruralidade frutícola, como a preservação da beleza paisagística agrícola e dos recursos ambientais no meio rural (OTANI et al., 2012). Também cabe indicar a presença de UCs em alguns dos municípios que compõe o CF, como a existência de uma Área de

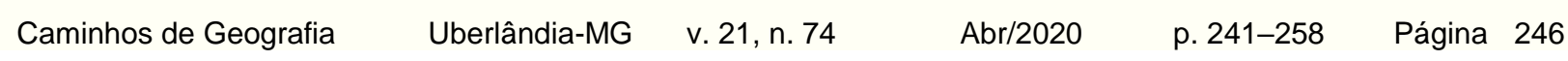


Proteção Ambiental (APA) que engloba a totalidade do município de Jundiaí, e parte dos municípios de Itupeva, Jarinu e Indaiatuba, bem como a existência de uma Reserva Biológica municipal na região da Serra do Japi, em Jundiaí, sendo que tais UCs objetivam proteger o maciço florestal da Serra do Japi e as bacias produtoras de água para abastecimento público (JUNDIAí, 1991; SÃO PAULO, 1998; SÃO PAULO 2006a; SÃO PAULO, 2006b).

Neste contexto, a manutenção e restauração dos fragmentos florestais nas propriedades rurais do CF adquire especial relevância, pelos serviços ecossistêmicos associados a estes maciços florestados, que ademais são elementos importantes na conformação da beleza cênica e paisagística própria da região. Desta forma, conhecer os impactos e potencialidades da aplicação da lei florestal brasileira nas propriedades do CF pode contribuir para o desenho de estratégias de desenvolvimento rural neste território, que incorporem a dimensão da qualidade ambiental e florestal em suas premissas.

É neste cenário que a presente pesquisa se insere. Buscou-se avaliar o panorama da cobertura florestal nas propriedades do CF, com foco no impacto da aplicação do art. 67 da LFB na instituição das RL e no potencial de geração de CRAs, a partir do tratamento e análise da base de dados do SICAR, associado à base de dados da Fundação Brasileira para o Desenvolvimento Sustentável - FBDS (2018) em ambiente de Sistema de Informações Geográficas (SIG).

Considerando que o registro dos imóveis no CAR é declaratório, o que pode ocasionar imprecisões técnicas e falhas no cadastramento, a entidade não governamental FBDS iniciou a partir de 2015 o projeto "Mapeamento em Alta Resolução dos Biomas Brasileiros", que produziu dados primários de uso e cobertura do solo, rede hidrográfica e APPs para todos os municípios brasileiros, em resolução de 05 metros, objetivando apoiar a implementação do CAR no território nacional. Os mapas de uso e ocupação do solo gerados neste projeto, e disponibilizados ao público em 2018, trazem, entre outras informações, a cobertura de vegetação nativa por município, oriundas do tratamento de imagens do satélite RapidEye, no ano base de 2013 (FBDS, 2018; Rezende et al., 2018).

O estudo partiu do acesso e do download dos dados públicos disponíveis em ambas as plataformas: no SICAR, com acesso pelo sítio eletrônico www.car.gov.br, e na FBDS, com acesso pelo sítio eletrônico www.geo.fbds.org.br.

Ambas as plataformas disponibilizam arquivos vetoriais georreferenciados em formato shapefile organizados por municípios, sendo que no SICAR os polígonos de interesse correspondem aos limites dos imóveis rurais cadastrados, e na plataforma da FBDS os dados utilizados foram do mapeamento de uso e cobertura do solo elaborado em escala 1:10.000, a partir de imagens de satélite de alta resolução correspondentes ao ano de 2013 (Rezende et al., 2018). Os shapefiles referentes aos CARs e ao mapeamento de uso e cobertura do solo da FBDS de cada um dos dez municípios do CF foram acessados em 23/05/2019.

Na sequência, os dados foram tratados no software livre de geoprocessamento QGIS versão 2.18 Las Palmas, associado aos complementos GRASS GIS e SAGA GIS. Todo o estudo foi realizado com três conjuntos de polígonos extraídos das plataformas base: área dos imóveis rurais a partir do SICAR, e área dos remanescentes de vegetação nativa e das APPs hídricas, projetadas a partir de córregos e nascentes, obtidas do mapeamento de uso e cobertura do solo da FBDS.

O tratamento dos shapefiles referentes aos imóveis envolveu: exclusão dos imóveis com cadastro cancelado, e conferência e correção dos valores dos módulos fiscais na tabela de atributos dos arquivos, que foram então mesclados em um único arquivo vetorial contemplando a totalidade dos dez municípios que compõe o CF.

Quanto aos shapefiles de uso e cobertura do solo, os polígonos referentes aos remanescentes de vegetação nativa foram extraídos da base de uso e cobertura do solo, que contempla outras categorias como área antropizada, silvicultura, área edificada e de espelhos d'água. Cabe indicar que para o 
presente estudo foram utilizadas duas categorias definidas no mapeamento da FBDS: formação florestal, que contempla a vegetação arbórea nativa com dossel contínuo, e formação não florestal, que contempla vegetação arbustiva nativa sem dossel contínuo (Rezende et al., 2018). Tal opção metodológica se deu em função do entendimento de que a categoria formação não florestal contempla áreas de vegetação nativa em processo inicial de regeneração, que no contexto do CF território inserido no bioma Mata Atlântica, são áreas de vegetação nativa protegidas no marco da Lei Federal 11.428/2006. Na sequência, os polígonos da vegetação nativa foram mesclados em um único arquivo vetorial contemplando os dez municípios de interesse.

Ainda em ambiente SIG, os arquivos foram transformados para projeção plana em sistema de referência de coordenadas SIRGAS2000 UTM 23k S. Depois, os shapefiles dos imóveis rurais foram separados em quatro layers, referentes aos minifúndios (imóveis com área de até 1 módulo fiscal), pequenas propriedades (com área superior a 1 módulo fiscal até 4 módulos fiscais), médias propriedades (com área superior a 4 módulos fiscais até 15 módulos fiscais) e grandes propriedades (imóveis com área superior a 15 módulos fiscais), a partir da operação "extrair por atributo". A correção do valor da área das propriedades, expressa em módulos fiscais para cada um dos municípios do CF conforme exposto na Tabela 1, foi fundamental para o sucesso desta operação.

Tabela 1 - Valor de módulo fiscal (MF) dos municípios que compõe o Circuito das Frutas.

\begin{tabular}{cc} 
Município & $\begin{array}{c}\text { Valor do módulo fiscal } \\
\text { (hectare) }\end{array}$ \\
\hline Atibaia & 16 \\
Indaiatuba & 10 \\
Itatiba & 12 \\
Itupeva & 10 \\
Jarinu & 12 \\
Jundiaí & 10 \\
Morungaba & 12 \\
Louveira & 10 \\
Valinhos & 10 \\
Vinhedo & 10 \\
\hline
\end{tabular}

Fonte - Os autores, adaptado de INCRA, 2019.

Depois, cada layer referente a cada categoria fundiária foi intersectado individualmente com o polígono da vegetação nativa, já mesclado para a totalidade do território do CF. O resultado desta intersecção foi a alocação dos maciços florestais em sobreposição ao limite das propriedades rurais do CF, já separadas segundo classes de tamanho a partir dos módulos fiscais. Também efetuou-se a intersecção do shapefile referente às APPs hídricas com os shapefiles das propriedades rurais e da cobertura florestal, de modo a verificar a incidência de APPs nas propriedades, bem como a presença ou ausência de vegetação nativa nestas áreas protegidas,

Na sequência, e com o uso da calculadora de campo do software QGIS, a área dos fragmentos florestais e APPs hídricas incidentes em cada um dos imóveis foram corrigidas. Após esta operação, verificou-se que as propriedades apresentavam geralmente mais de um fragmento florestal incidente em seu interior. Assim, a área dos diversos fragmentos florestais alocados nas propriedades foi somada a partir do 
complemento Group Stats, o que permitiu obter o resultado do montante total de vegetação nativa, dentro e fora de APPs, incidente em cada uma das propriedades rurais delimitadas no CAR. Depois, a tabela de atributos já corrigida foi exportada para o software Excel, para fins de obtenção dos resultados, que serão apresentados e discutidos na sequência.

\section{RESULTADOS E DISCUSSÃO}

A metodologia empregada permitiu tratar e analisar as informações de limite das propriedades e fragmentos de vegetação nativa obtidas do CAR e do projeto Mapeamento em Alta Resolução dos Biomas Brasileiros (FBDS, 2018; Rezende et al., 2018; SICAR 2019), com vistas a traçar o panorama fundiário do CF, ou seja, como as propriedades rurais estão distribuídas segundo as classes de tamanho definidas na Lei 8.629/1993, e a verificar o quanto de vegetação nativa incide em cada imóvel rural localizado no CF, dentro e fora de APP, o que permitiu posteriormente estimar o impacto do art. 67 da LFB e da oferta e demanda de CRAs neste território.

A análise da estrutura fundiária de um determinado território passou a ser elemento importante a partir da publicação da Lei 12.651/2012, já que as disposições transitórias estabelecidas no âmbito do PRA permitem cenários distintos de restauração e/ou proteção florestal em função do tamanho dos imóveis rurais. Assim, conhecer a estrutura fundiária de um território permite antever de que forma aquele território corresponderá às disposições e restrições da lei florestal (GAVIOLI, 2017).

No caso do CF, os resultados obtidos indicam que o território é fortemente marcado pela presença das pequenas propriedades, com área de até quatro módulos fiscais, que representam $91,60 \%$ dos imóveis rurais cadastrados no CAR. Deste universo, que soma 5.298 imóveis rurais, 4.066 cadastros (ou 70,30\% do total) são de minifúndios, isto é, imóveis com área inferior a um módulo fiscal, conforme apresentado na Tabela 2.

Tabela 2 - Estrutura fundiária do Circuito das Frutas.

\begin{tabular}{|c|c|c|c|c|}
\hline \multirow{2}{*}{$\begin{array}{l}\text { Classe de tamanho } \\
\text { (módulo fiscal) }\end{array}$} & \multicolumn{2}{|c|}{ Imóveis rurais } & \multicolumn{2}{|c|}{ Área } \\
\hline & № & $\%$ & Hectares & $\%$ \\
\hline 0 a 01 - minifúndio & 4.066 & 70,30 & $19.021,19$ & 15,21 \\
\hline$>01$ a 04 - pequena propriedade & 1.232 & 21,30 & $28.349,93$ & 22,67 \\
\hline Agrupado 0 a 4 & 5.298 & 91,60 & $47.371,12$ & 37,88 \\
\hline > 04 a 15 - média propriedade & 360 & 6,22 & $30.223,28$ & 24,17 \\
\hline$>15$ - grande propriedade & 126 & 2,18 & $47.454,63$ & 37,95 \\
\hline Total & 5.784 & 100,00 & $125.049,03$ & 100,00 \\
\hline
\end{tabular}

Fonte - Os autores, a partir dos dados do SICAR (2019).

Embora representem $91,60 \%$ dos imóveis cadastrados no CF, as pequenas propriedades somam $47.371,12$ hectares, ou $37,88 \%$ da área cadastrada no território. O restante da área cadastrada está distribuído entre 486 médias e grandes propriedades, que não são beneficiadas pelo art. 67 da lei florestal brasileira.

No total, os resultados indicam que no CF existem 5.784 propriedades rurais cadastradas no CAR, que somam área total de $125.049,03$ hectares, ou $52,43 \%$ da área total do território, que é de cerca de

$\begin{array}{lllll}\text { Caminhos de Geografia } & \text { Uberlândia-MG } & \text { v. 21, n. } 74 & \text { Abr/2020 } & \text { p. 241-258 }\end{array}$ Página 249


238.478,00 hectares (CAMARGO JUNIOR et al., 2017). A distribuição das propriedades rurais cadastradas no CAR, segundo classes de tamanho, é representada no mapa da Figura 2.

Figura 2 - Circuito das Frutas paulista: estrutura fundiária.

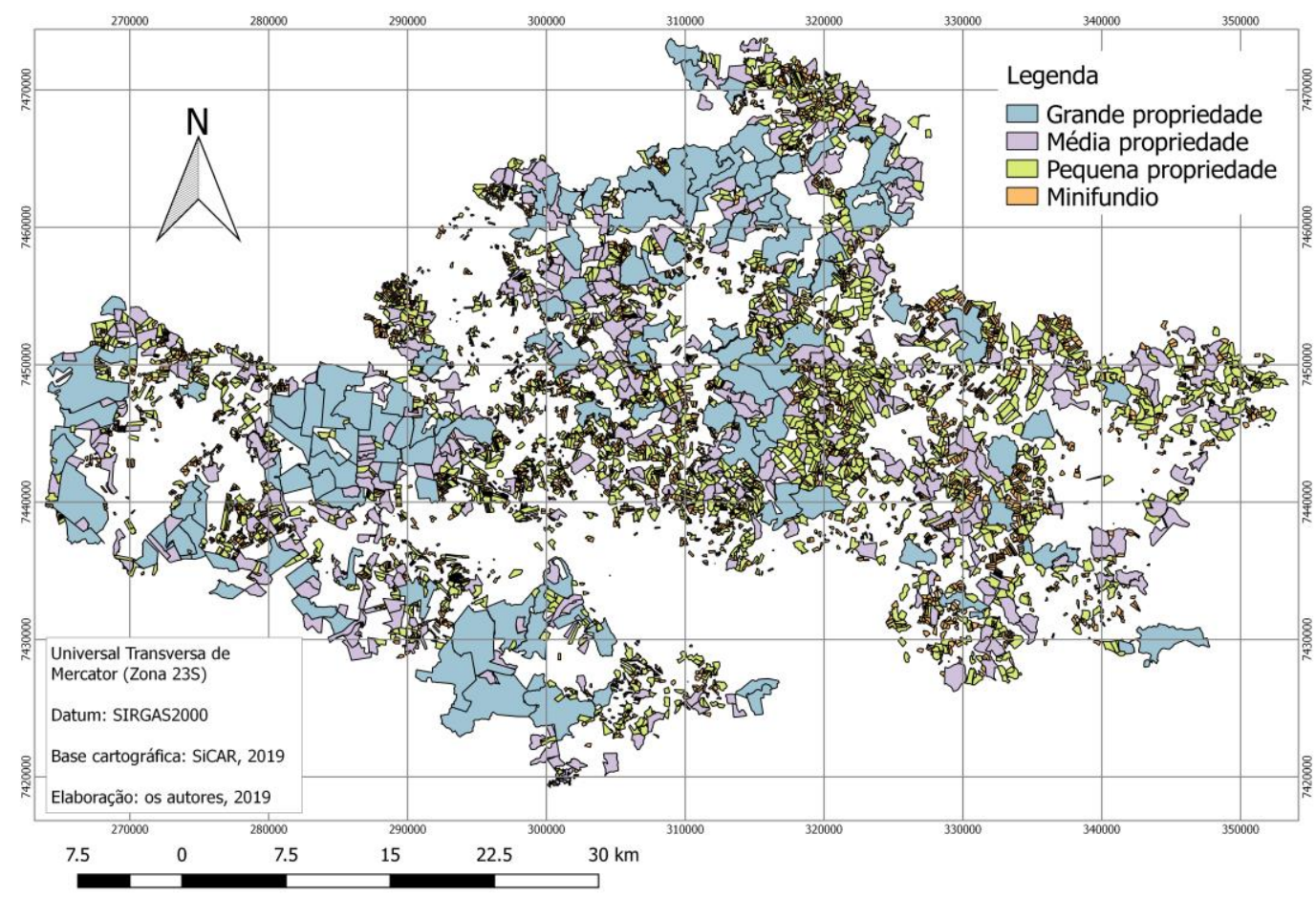

Fonte - Os autores, 2019.

Nestes imóveis cadastrados, de acordo com os dados da FBDS (2018), incidem 20.479,85 hectares de APPs hídricas, das quais $8.488,51$ hectares $(41,44 \%)$ são ocupados por vegetação nativa, e os $11.991,34$ hectares restantes $(58,56 \%)$ são de APPs antropizadas, ocupadas por culturas agrícolas, silvicultura ou edificações.

A distribuição destas APPs hídricas em relação à estrutura fundiária do território é apresentada na Tabela 3:

Tabela 3 - Uso de solo em Áreas de Preservação Permanente hídricas distribuídas sobre os imóveis rurais do Circuito das Frutas.

\section{Área de Preservação Permanente - APP hídrica}

\section{Classe de tamanho (módulo fiscal)}

(em hectares)

\begin{tabular}{ccc}
\hline $\begin{array}{c}\text { APP recoberta com } \\
\text { vegetação nativa }\end{array}$ & $\begin{array}{c}\text { APP sem } \\
\text { vegetação nativa }\end{array}$ & APP total \\
$2.860,56$ & $5.019,52$ & $7.880,08$ \\
$2.105,22$ & $2.979,67$ & $5.084,89$ \\
$3.522,73$ & $3.992,15$ & $7.514,88$ \\
$8.488,51$ & $11.991,34$ & $20.479,85$
\end{tabular}

Fonte - Os autores, a partir dos dados do SICAR (2019) e FBDS (2018).

$\begin{array}{lllll}\text { Caminhos de Geografia } \quad \text { Uberlândia-MG } & \text { v. 21, n. } 74 & \text { Abr/2020 } & \text { p. 241-258 Página } 250\end{array}$


No que se refere à cobertura florestal, as informações do mapeamento da FBDS (2018) indicam que no CF incidem 32.533,23 hectares de vegetação nativa, distribuídos nos imóveis rurais cadastrados, sendo $32.309,85$ hectares referentes à formações florestais com dossel contínuo e 223,38 hectares referentes à formações arbustivas ou de florestas em estágios iniciais de sucessão, sem dossel contínuo. Este montante total de vegetação nativa equivale a $26,01 \%$ da área total cadastrada dos imóveis, e a cerca de $13,64 \%$ da área total do CF.

Observa-se que no computo geral, a área de vegetação nativa incidente no CF é superior a $20 \%$ da área total dos imóveis cadastrados, o que em princípio sugere atendimento às obrigações da instituição de RL em todos os imóveis, consoante ao art. 12 da LFB. No entanto, há de se observar que estes maciços florestais estão desigualmente distribuídos sobre as propriedades cadastradas. O mapa da Figura 3 demonstra a distribuição da cobertura de vegetação nativa e das APPs hídricas, sobre os imóveis rurais cadastrados no CAR de acordo com as diferentes classes de tamanho.

Figura 3 - Circuito das Frutas paulista: estrutura fundiária, cobertura de vegetação nativa e presença de APPs hídricas.

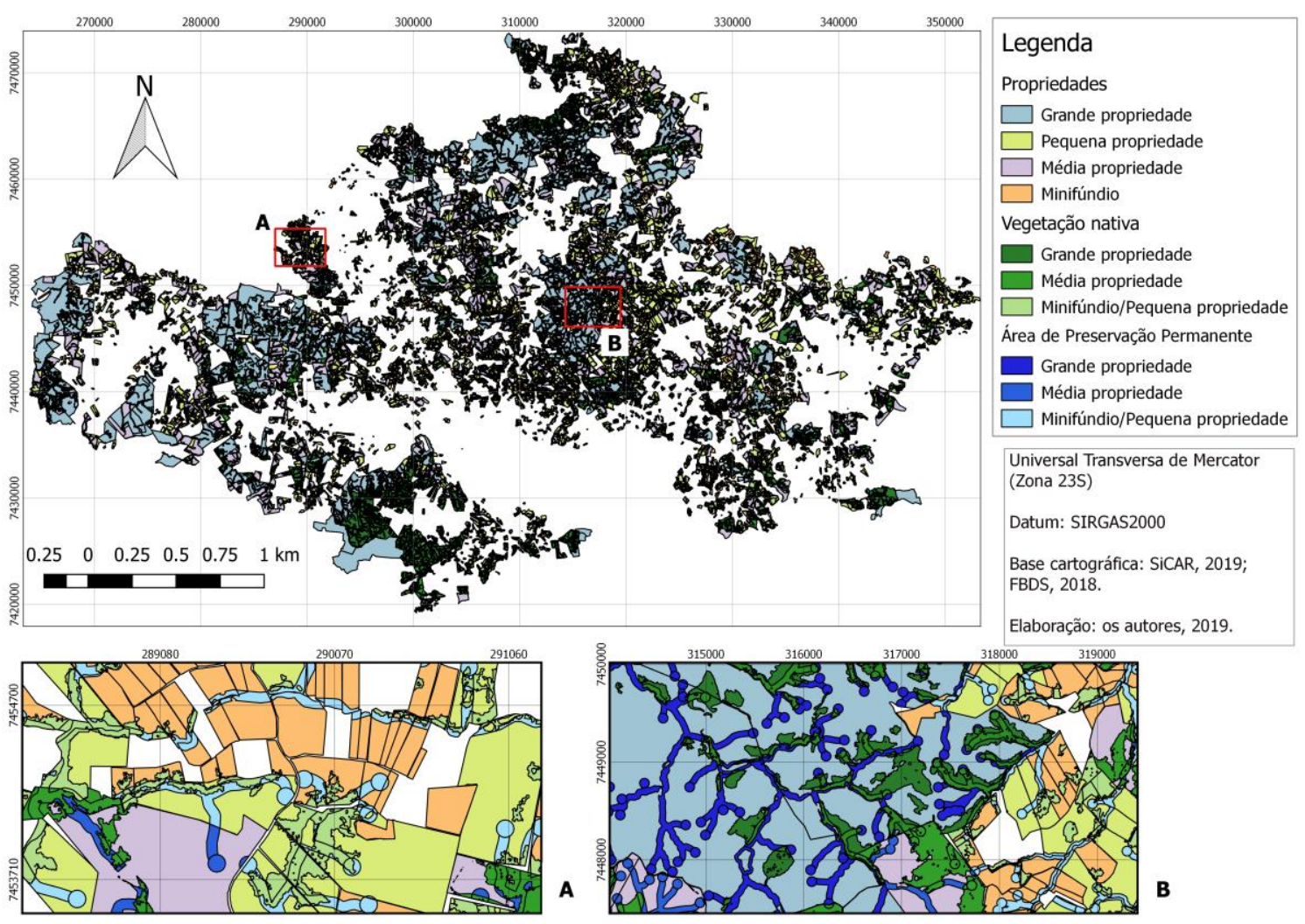

Fonte - Os autores, 2019.

Para se avaliar o impacto potencial do art. 67 da LFB sobre as pequenas propriedades do território, bem como para estimar qual é a necessidade de restauração florestal para conformação de RL obrigatória nas médias e grandes propriedades, e se há potencial para instituição de CRAs neste território, é necessário conhecer como esta distribuição desigual de 32,5 mil hectares de vegetação nativa ocorre sobre as diferentes categorias fundiárias que conformam o CF.

Para tanto, os dados obtidos a partir das operações de intersecção realizadas em ambiente SIG e representadas no mapa da Figura 3, foram analisados em planilhas, ao que foi possível separar os imóveis de cada categoria fundiária em dois conjuntos: imóveis com menos de $20 \%$ de cobertura florestal, 
incluindo aqueles sem qualquer remanescente de vegetação nativa, e imóveis com $20 \%$ ou mais de cobertura florestal.

Para o primeiro grupo, dos imóveis com menos de $20 \%$ de cobertura florestal, foram realizados os cálculos da área de RL devida, que corresponde a $20 \%$ da área total das propriedades. Depois, subtraiuse deste montante a área recoberta por vegetação nativa nos imóveis, o que resultou na informação do déficit de RL. Nas propriedades de até 04 módulos fiscais, inclusive minifúndios, este déficit corresponde à área de RL que deixará de ser objeto de restauração florestal, a partir da aplicação do art. 67 da LFB. Nas médias e grandes propriedades, o déficit compreende a área de RL que deverá ser restaurada, ou que deverá ser objeto de compensação por meio da aquisição de CRAs Também avaliou-se a sobreposição existente entre cobertura florestal e APPs.

Os resultados obtidos a partir da análise dos dados são apresentados na Tabela 4.

Tabela 4 - Imóveis com menos de $20 \%$ de cobertura florestal: quantidade, área, RL devida, cobertura florestal e déficit de RL.

\begin{tabular}{|c|c|c|c|c|c|c|c|c|c|}
\hline \multirow{2}{*}{$\begin{array}{l}\text { Categoria } \\
\text { fundiária }\end{array}$} & \multicolumn{2}{|c|}{ Imóveis } & \multicolumn{2}{|c|}{ Área } & \multirow{2}{*}{$\begin{array}{c}\text { RL devida } \\
-20 \% \text { da } \\
\text { área }\end{array}$} & \multirow{2}{*}{$\begin{array}{c}\text { Cobertura } \\
\text { florestal }\end{array}$} & \multirow{2}{*}{$\begin{array}{c}\begin{array}{c}\text { Cobertura } \\
\text { florestal em } \\
\text { APP }\end{array} \\
\text { Hectares }\end{array}$} & \multicolumn{2}{|c|}{$\begin{array}{c}\text { Déficit de } R L \text { (RL devida } \\
\text { - cobert. ftal.) }\end{array}$} \\
\hline & № & $\%^{*}$ & Hectares & $\%^{*}$ & & & & Hectares & $\%$ \%* \\
\hline Pequeno & 3.504 & 66,14 & $27.838,46$ & 58,77 & $5.567,69$ & $1.768,98$ & 666,76 & $3.798,72$ & 68,22 \\
\hline Médio & 187 & 51,94 & $14.963,87$ & 49,51 & $2.992,77$ & $1.374,65$ & 457,15 & $1.618,12$ & 54,06 \\
\hline Grande & 55 & 43,65 & $20.362,30$ & 42,91 & $4.072,46$ & $2.235,06$ & 730,96 & $1.837,40$ & 45,11 \\
\hline Total & 3.746 & 64,76 & $63.164,63$ & 50,51 & $12.632,92$ & $5.378,69$ & $1.854,87$ & $7.254,23$ & 57,42 \\
\hline
\end{tabular}

Da Tabela 4, verifica-se que mais da metade dos imóveis rurais do CF, nas três categorias fundiárias consideradas, se apresentam com cobertura florestal inferior a $20 \%$. Em relação às pequenas propriedades, beneficiadas pelo art. 67 da LFB, os imóveis com menos de $20 \%$ de vegetação nativa ocupam área de quase 28 mil hectares, ou $58,77 \%$ da área ocupada pelo total das pequenas propriedades no CF. Considerando o art. 12 da LFB, estes imóveis deveriam, no conjunto, instituir cerca de 5,5 mil hectares de RL, restaurando os maciços florestais insuficientes para compor o percentual mínimo de $20 \%$ de RL.

Neste universo das pequenas propriedades, os dados revelaram que existem 1.768 .98 hectares de vegetação nativa nos imóveis, dos quais 666,76 hectares incidem em APPs hídricas. Assim, há um déficit calculado de RL para este conjunto das pequenas propriedades de $3.798,72$ hectares. Este montante representa a área cuja recuperação florestal está isenta nos pequenos imóveis, no marco da aplicação do art. 67 da LFB. Em outros termos, a aplicação da disposição transitória da LFB no CF possibilita uma perda da ordem de 3,79 mil hectares de RL, ou 68,22\% da RL que seria exigível pela Lei 4.771/1965.

No caso das médias e grandes propriedades com cobertura florestal inferior a $20 \%$, estas representam $49,51 \%$ e $42,91 \%$ da área total das médias e grandes propriedades, respectivamente. O déficit de RL calculado para ambas as categorias fundiárias foi da ordem de 3,45 mil hectares. Considerando que as médias e grandes propriedades não se beneficiam do art. 67 da LFB, estes 3,45 mil hectares deverão ser objeto de ações de restauração florestal, havendo ainda a possibilidade da compensação deste déficit de $\mathrm{RL}$, por meio da aquisição de CRAs. Considerando as três categorias fundiárias em seus conjuntos, o déficit de áreas florestadas para compor RL nos imóveis com menos de $20 \%$ de cobertura de vegetação nativa foi calculado em 7.254,23 hectares, o que representa $57,42 \%$ da área de $R L$ devida.

A sistematização dos dados também permitiu diagnosticar o panorama dos imóveis rurais com $20 \%$ ou mais de cobertura florestal, nas três categorias fundiárias, conforme Tabela 5. 
Estrutura fundiária e conservação de florestas em propriedades rurais do Circuito das Frutas/SP: uma análise dos impactos da Lei 12.651/2012 na conformação de Reservas Legais e Cotas de Reserva Ambiental
Felipe Rosafa Gavioli

Raquel Carnivalle Silva Melillo

Cristiane Ronchi de Oliveira

Tabela 5 - Imóveis com $20 \%$ ou mais de cobertura florestal: quantidade, área, RL devida, cobertura florestal e saldo de vegetação nativa.

\begin{tabular}{|c|c|c|c|c|c|c|c|c|c|}
\hline \multirow[t]{2}{*}{$\begin{array}{l}\text { Categoria } \\
\text { fundiária }\end{array}$} & \multicolumn{2}{|c|}{ Imóveis } & \multicolumn{2}{|c|}{ Área } & \multirow{2}{*}{$\begin{array}{c}\text { RL devida - } \\
\mathbf{2 0 \%} \text { da área } \\
\text { Hectares }\end{array}$} & \multirow{2}{*}{$\begin{array}{c}\begin{array}{c}\text { Cobertura } \\
\text { florestal }\end{array} \\
\text { Hectares }\end{array}$} & \multirow{2}{*}{$\begin{array}{c}\text { Cobertura } \\
\text { florestal } \\
\text { em APP }\end{array}$} & \multicolumn{2}{|c|}{$\begin{array}{c}\text { Saldo de vegetação } \\
\text { nativa (Cobert. ftal - RL } \\
\text { devida) }\end{array}$} \\
\hline & № & $\% *$ & Hectares & \%* & & & & Hectares & \%** \\
\hline Pequeno & 1.794 & 33,86 & $19.532,67$ & 41,23 & $3.906,53$ & $9.250,29$ & $2.193,80$ & $5.343,76$ & 136,79 \\
\hline Médio & 173 & 48,06 & $15.259,41$ & 50,49 & $3.051,88$ & $6.594,08$ & $1.648,07$ & $3.542,19$ & 116,07 \\
\hline Grande & 71 & 56,35 & $27.092,34$ & 57,09 & $5.418,47$ & $11.310,18$ & $2.791,77$ & $5.891,75$ & 108,73 \\
\hline Total & 2.038 & 35,23 & $61.884,42$ & 49,48 & $12.376,88$ & $27.154,55$ & $6.633,64$ & $14.777,67$ & 119,39 \\
\hline
\end{tabular}

* Porcentagem em relação ao total de propriedades e total de área por categoria fundiária conforme Tabela 2.

** Porcentagem em relação a área de Reserva Legal devida.

Fonte - Os autores, a partir dos dados do SICAR (2019) e FBDS (2018).

Cerca de um terço dos imóveis rurais do CF se apresentam com cobertura florestal igual ou superior a $20 \%$. Em relação às categorias fundiárias, a maior parte das grandes propriedades (mais de $50 \%$ destas) se apresentam com cobertura florestal igual ou superior a $20 \%$. A maior porção dos maciços florestais incide nas grandes propriedades (11 mil hectares), seguida das pequenas propriedades, que abrigam cerca de 9 mil hectares de vegetação nativa.

Estes imóveis com mais de $20 \%$ de cobertura florestal ocupam área de $61.884,42$ hectares, ou $49,48 \%$ da área total cadastrada das propriedades do CF. A RL devida para este universo de propriedades é de $12.376,88$ hectares (20\% da área cadastrada), sendo que os dados da FBDS (2018) apontaram para a existência de 27.154,55 hectares de cobertura florestal nestas propriedades, sendo 6.633,64 hectares em APPs hídricas. Este montante de vegetação nativa é suficiente para compor a RL devida nestas propriedades, com saldo de vegetação excedente de 14.777,67 hectares.

Este saldo seria, em princípio, mais do que suficiente para compensar, mediante criação de CRAs, o déficit de RL observado nas propriedades com cobertura florestal inferior a $20 \%$, inclusive considerando as pequenas propriedades beneficiadas pelo art. 67 da LFB.

Se considerarmos que a vegetação nativa incidente nas pequenas propriedades, ainda que conformem RL, podem também compor CRAs conforme o art. 44 da LFB, a oferta potencial de CRAs no CF seria de $20.453,21$ hectares, que é o resultado da soma dos saldos de cobertura florestal das médias e grandes propriedades, com o montante total de vegetação existente nas pequenas propriedades, inclusive naquelas com menos de $20 \%$ de cobertura florestal. Para esta oferta, a demanda potencial de déficit de $\mathrm{RL}$ das médias e grandes propriedades a ser compensado é de 3.455,52 hectares, seguindo o mesmo padrão de desproporcionalidade entre oferta e demanda de CRAs observado por outros estudos, como o de Freitas et al. (2016), que identificou uma oferta de 1,525 milhões de hectares de CRAs para uma demanda de 1,141 milhões de hectares dentro do estado de São Paulo, ou o de Cruz et al. (2020), que aponta para uma oferta de CRAs 2,76 vezes superior à demanda potencial no bioma Mata Atlântica no estado de Minas Gerais.

Afora a desproporcionalidade entre oferta e demanda potencial observada, cabe ainda efetuar uma análise da adicionalidade que estes 20.453,21 hectares potenciais de oferta de CRAs no CF podem oferecer para a conservação da biodiversidade, sendo que a adicionalidade é obtida quando há instituição de CRAs sobre fragmentos florestais não protegidos por outros instrumentos legais.

Cumpre indicar que no presente estudo se adota uma conceituação de adicionalidade diferente da adotada por Freitas et al. (2016): enquanto estes autores entendem que os fragmentos florestais do bioma Mata Atlântica, como é o caso das florestas incidentes no CF, localizados fora de APP ou de RL não garantem adicionalidade por serem protegidos pela chamada Lei da Mata Atlântica - Lei 11.428/2006; neste trabalho considera-se que qualquer remanescente florestal localizado fora de APP ou para além da $\mathrm{RL}$ obrigatória de $20 \%$ está sujeito a supressão legal, e portanto garante adicionalidade; uma vez que a Lei 11.428/2006 possibilita a supressão legal da vegetação nativa em estágio inicial de regeneração, localizada nos imóveis rurais, para qualquer finalidade (i.e. conversão de florestas em agricultura,

\begin{tabular}{|c|c|}
\hline & Uberlândia-MG \\
\hline
\end{tabular}


Estrutura fundiária e conservação de florestas em propriedades rurais do Circuito das Frutas/SP: uma análise dos impactos da Lei 12.651/2012 na conformação de Reservas Legais e Cotas de Reserva Ambiental
Felipe Rosafa Gavioli

Raquel Carnivalle Silva Melillo

Cristiane Ronchi de Oliveira

pastagens, edificações, entre outros), e no caso da vegetação nativa em estágio médio ou avançado de regeneração em imóveis rurais, a supressão legal se viabiliza para as obras de utilidade pública e interesse social conforme definido na legislação, como obras de saneamento por exemplo (BRASIL, 2006).

Ademais, na hipótese de o fragmento florestal de Mata Atlântica estar alocado em perímetro urbano definido pelos municípios, as regras são mais flexíveis, com maiores possibilidades de supressão dos maciços florestais em estágio médio e avançado de regeneração, conforme estabelecem os artigos 8,14 , 30 e 31 do diploma legal (BRASIL, 2006).

Deste modo, parte-se do princípio de que há adicionalidade na instituição de CRAs em fragmentos florestais de Mata Atlântica localizados fora de APP ou RL, visto que se em estágio inicial de regeneração tais maciços podem ser suprimidos legalmente, e observando também que modificações nas leis de uso e ocupação do solo municipais, com expansão dos perímetros urbanos para áreas hoje localizadas em perímetro rural, sujeitam os fragmentos florestais em estágio médio de regeneração hoje existentes nestas localidades à possibilidade de supressão regular.

Nesta ótica, verifica-se que dos 20.453,21 hectares potenciais para a conformação de CRAs, 1.768,98 hectares são de vegetação nativa incidente em pequenas propriedades com menos de $20 \%$ de cobertura florestal; 4.439,84 hectares são de vegetação excedente incidente nas médias e grandes propriedades e que estão em APPs hídricas já protegidas pela legislação florestal; e 6.100,33 hectares são referentes à vegetação nativa incidente em $R L$ obrigatória e em APPs hídricas nas pequenas propriedades com mais do que $20 \%$ de cobertura florestal.

Assim, há 12.309,15 hectares do potencial de CRAs em florestas já imunes de corte, seja pela proteção dada por RL obrigatória ou pela localização em APP, ao que as CRAs com alguma adicionalidade de proteção ambiental, isto é, fragmentos florestais passíveis de supressão legal no marco da Lei 11.428/2006, conformam 8.144,06 hectares. Neste sentido, a regulamentação das transações das CRAs deve privilegiar a alocação de cotas nestes maciços florestais cuja supressão legal é possível, de modo a garantir adicionalidade do instrumento de CRA na conservação dos fragmentos florestais e da biodiversidade. Cumpre ressaltar que mesmo estes 8 mil hectares de florestas que podem conformar CRAs com adicionalidade seriam suficientes para compensar o déficit de RL observado nas médias e grandes propriedades, que é de cerca de 3,45 mil hectares.

Com a publicação da Lei 12.651/2012, a regularização ambiental de imóveis rurais passou a ser condicionada pelo seu tamanho, conformando cenários de proteção e de recomposição florestal dos territórios em forte vinculação às estruturas fundiárias estabelecidas.

$\mathrm{Na}$ realidade territorial do $\mathrm{CF}$, a presença das pequenas propriedades é marcante, já que representam $91,60 \%$ das propriedades cadastradas no SICAR, e 37,88\% da área dos imóveis. De outro lado, e em termos de área cadastrada, as grandes propriedades são relevantes, sendo que conformam $37,95 \%$ da área do CF, apesar de representarem somente $2,18 \%$ das propriedades cadastradas.

No conjunto, e com base nos dados do SICAR e da FBDS, as propriedades do CF apresentam 32.533,24 hectares de cobertura de florestas nativas. A maior parte da área ocupada por florestas está distribuída nas grandes propriedades, que abrigam cerca de 13,5 mil hectares de vegetação nativa. Na sequência, estão as pequenas propriedades, com cerca de 11 mil hectares de cobertura florestal. A análise dos dados também revelou que sobre as propriedades do CF incidem cerca de 20 mil hectares de APPs hídricas, das quais quase 12 mil hectares estão desprovidos de vegetação nativa.

De modo a avaliar as correlações existentes entre a cobertura florestal identificada e o comportamento do instrumento de $\mathrm{RL}$, as propriedades rurais foram divididas em dois grupos no presente estudo: aquelas com menos de $20 \%$ de cobertura florestal, e as que apresentam $20 \%$ ou mais de cobertura florestal.

A maior parte das propriedades do CF $(64,76 \%$ dos imóveis) apresenta cobertura florestal inferior a $20 \%$. Este universo representa 50,51\% da área cadastrada do CF. A aplicação do art. 67 da LFB neste contexto implicou em redução de $3.798,72$ hectares da área de $\mathrm{RL}$ obrigatória das pequenas propriedades, ou $68,23 \%$ da RL que seria exigível ante a aplicação da Lei 4.771/1965, ou seja, sem considerar a possibilidade de flexibilização do instrumento RL prevista no art. 67 da LFB. O déficit de RL calculado para as médias e grandes propriedades foi de 3.455,52 hectares, déficit este que constitui a demanda potencial por CRAs no território estudado.

Deste modo, a perda de RL obrigatória para as pequenas propriedades no CF é significativa frente ao montante de $R L$ devida para as médias e grandes propriedades, e a aplicação do art. 67 da lei florestal 
Estrutura fundiária e conservação de florestas em propriedades rurais do Circuito das Frutas/SP: uma análise dos impactos da Lei 12.651/2012 na conformação de Reservas Legais e Cotas de Reserva Ambiental
Felipe Rosafa Gavioli

Raquel Carnivalle Silva Melillo

Cristiane Ronchi de Oliveira

brasileira neste território constitui, ao nosso ver, em impacto relevante sobre a conservação florestal, uma vez que a aplicação de tal dispositivo legal acarretará em perda potencial de 3,79 mil hectares que poderiam ser objeto de projetos de restauração ecológica, com consequente incremento de serviços ecossistêmicos (ALEXANDER et al., 2016).

Quanto aos imóveis que apresentam cobertura florestal igual ou superior a $20 \%$, estes representam $35,23 \%$ das propriedades e $49,48 \%$ da área cadastrada. A RL devida neste universo é de $12.376,88$ hectares, sendo que tais imóveis apresentam, no conjunto, cobertura florestal em 27.154,55 hectares, com um saldo de vegetação nativa excedente à conformação da RL obrigatória de 14.777,67 hectares.

Este saldo, somado à vegetação nativa que incide nas pequenas propriedades totaliza uma oferta potencial de CRAs de $20.453,21$ hectares, portanto, suficiente para compensar o déficit de RL observado para as médias e grandes propriedades com cobertura florestal inferior a $20 \%$. Tais resultados apontam para uma desproporcionalidade entre oferta e demanda potencial por CRAs no CF, com oferta bastante superior a demanda, em consonância com os estudos já citados de Freitas et al. (2016), e Cruz et al. (2020).

Destes 20 mil hectares potenciais para conformar CRAs, têm-se que 8.144,06 hectares apresentam adicionalidade para a conservação da biodiversidade, já que estão sujeitos à supressão regular, ao passo que 12.309,15 hectares não apresentam adicionalidade por serem florestas que já se encontram protegidas a título de APP nas pequenas, médias e grandes propriedades ou como RL obrigatória das pequenas propriedades, e que mesmo assim podem constituir CRAs conforme disposições da LFB.

Em que pese a existência de UCs de uso sustentável e de proteção integral em parte do território do CF, o presente estudo foi limitado à análise considerando as disposições da LFB, sem abordar as especificidades advindas da presença destas UCs. Trabalhos posteriores poderão estimar o impacto das UCs existentes no território na conformidade legal dos imóveis rurais no que se refere a adequação florestal.

\section{CONSIDERAÇÕES FINAIS}

A partir do estudo realizado, conclui-se que a aplicação do art. 67 da LFB no território do CF constitui impacto relevante sobre a conservação florestal nas paisagens agrícolas, já que implica em anistia da instituição e recomposição florestal de 3,7 mil hectares de RLs nas pequenas propriedades rurais do território.

De outro lado, a existência de 8.144,06 hectares de vegetação nativa excedente à $R L$ e localizada fora de APP, que são passíveis de supressão legal, podem constituir CRAs com adicionalidade em montante suficiente para compensar o déficit de $R L$ das propriedades com menos de $20 \%$ de cobertura florestal em todas as categorias fundiárias.

Assim, e na realidade estudada, o atendimento à exigência legal de manter $20 \%$ de todos os imóveis com cobertura florestal, com possibilidade de compensação via aquisição de CRA, seria possível com o montante de vegetação nativa hoje existente no território.

Esta observação é relevante, na medida em que aponta para uma potencialidade de aquisição de CRAs em locais próximos aos do déficit de RL observado. Uma das grandes críticas ao dispositivo da CRA é a possibilidade de aquisição das cotas em escala de bioma, conforme estabelece 0 art. 48 da Lei 12.651/2012, sem levar em consideração outros critérios como por exemplo a localização em mesma bacia hidrográfica ou mesmo critérios de proximidade geográfica (MACHADO, 2016). A adoção de um recorte amplo do ponto de vista espacial, como o bioma, para a compensação de RL por intermédio das CRAs pode criar um movimento no qual regiões de economia dinâmica e com preço das terras elevados, tendem a deslocar, via aquisição de CRAs, o seu passivo ambiental de recomposição de RL para regiões desvalorizadas, criando um desbalanço entre regiões de passivo e regiões de ativo ambiental, desbalanço este que embora legalmente aceitável, afeta negativamente a conservação dos recursos florestais e da biodiversidade em paisagens antropizadas nas regiões de economia mais dinâmica (LAUDARES et al., 2019). De outro lado, a adoção de um "olhar local" no estabelecimento destes arranjos de compensação de RLs impacta positivamente a adicionalidade do mecanismo, e garante que os benefícios da conservação florestal, tais como o sequestro de carbono ou a produção de água, fiquem localizados. Ademais, a limitação da aquisição de CRAs em escalas locais pode impulsionar a restauração ecológica de áreas degradadas nestes recortes definidos, já que o universo de CRAs disponíveis para aquisição objetivando a regularização florestal dos imóveis rurais seria menor (GIANNICHI et al., 2019). 
Neste sentido, e a partir dos resultados do estudo ora apresentado, entende-se que as regulamentações estaduais do PRA podem e devem estabelecer mecanismos de direcionamento da aquisição de CRAs em regiões próximas aos do passivo de $\mathrm{RL}$ observado, e considerando critérios de adicionalidade,/ o que contribuiria para a eficácia ambiental do dispositivo. Ademais, a mobilização destes maciços florestais excedentes como CRA impedem a supressão, ainda que regular, destas áreas e conversão para outros usos, com claras implicações positivas para a conservação da biodiversidade.

\section{REFERÊNCIAS}

AGUIAR, R; ENDRES, J.M; TAYLOR, C; EVANS, S. Public Conservation Policies on Private Land: A Case Study of the Brazilian Forest Code and Implications for the Agro-Industry Sector. Pace Environmental $\begin{array}{llll}\text { Law } & \text { Review, } & \text { v. } & 34,\end{array}$ https://digitalcommons.pace.edu/pelr/vol34/iss2/3..

ALEXANDER, S; ARONSON, J; WHALEY, O; LAMB, D. The relationship between ecological restoration and the ecosystem services concept. Ecology and Society v. 21, n.34, 2016. http://dx.doi.org/10.5751/ES-08288-210134

BARRAL, M.P; BENAYAS, J.M.R; MELI, P; MACEIRA, N.O. Quantifying the impacts of ecological restoration on biodiversity and ecosystem services in agroecosystems: a global meta-analysis. Agriculture, Ecosystems and Environment, v. 202, p.223-231. 2015. https://doi.org/10.1016/i.agee.2015.01.009

BRANCALION P.H.S; GARCIA, L.C; LOYOLA, R; RODRIGUES, R.R; PILLAR, V.D; LEWINSOHN, T.M. A critical analysis of the Native Vegetation Protection Law of Brazil (2012): updatesand ongoing initiatives. Natureza \& Conservação, v. 14, p. 1-15, 2016. https://doi.org/10.1016/i.ncon.2016.03.004

BRANCALION, P.H.S; MELO, F.P.L; TABARELLI, M; RODRIGUES, R.R. Restoration reserves as biodiversity safeguards in human-modified landscapes. Natureza \& Conservação, v.11, n. 2, p. 186-190, 2013. http://dx.doi.org/10.4322/natcon.2013.029

BRASIL. Lei no 11.428 de 22 de dezembro de 2006. Dispõe sobre a utilização e proteção da vegetação nativa do Bioma Mata Atlântica e dá outras providências. Diário Oficial da União, Brasília: 26 de dezembro 2006. Disponível em: http://www.planalto.gov.br/ccivil 03/ Ato2004-2006/2006/Lei/L11428.htm. Acesso em: 06 dez.2019.

BRASIL. Instrução Normativa no 02 de 05.05.2014 do Ministério do Meio Ambiente. Dispõe sobre procedimentos para a integração, execução e compatibilização do Sistema de Cadastro Ambiental Rural SiCAR e define os procedimentos gerais do Cadastro Ambiental Rural. Diário Oficial da União, Brasília: 05 de maio 2014. Disponível em: http://www.car.gov.br/leis/IN_CAR.pdf. Acesso em: 10 ago.2019.

BRASIL. Lei no 12.651 de 25 de maio de 2012. Dispõe sobre a proteção da vegetação nativa; altera as Leis nos 6.938, de 31 de agosto de 1981, 9.393, de 19 de dezembro de 1996, e 11.428, de 22 de dezembro de 2006; revoga as Leis nos 4.771, de 15 de setembro de 1965, e 7.754, de 14 de abril de 1989, e a Medida Provisória no 2.166-67, de 24 de agosto de 2001; e dá outras providências. Diário Oficial da União, Brasília: 28 maio 2012a. Disponível em: http://www.planalto.gov.br/ccivil_03/_Ato20112014/2012/Lei/L12651.htm. Acesso em: 10 ago.2019. BURKHARD, B; KROLL, F; MÜLLER, F; WINDHORST, W. Landscape's capacities to provide ecosystem services - a concept for land-cover based assessments. Landscape Online, v.15. p.1-22. 2009. https://doi.org/10.3097/LO.200915

CAMARGO JUNIOR, A.A.; GALDINO, S; QUARTAROLI, C.F; ALVAREZ, I.A. Geração de modelo digital de elevação do Circuito das Frutas do estado de São Paulo a partir de mapas topográficos e imagens de alta resolução espacial. In: 11 Congresso Interinstitucional de Iniciação Científica, 2017, Campinas. Anais do $11^{\circ}$ Congresso Interinstitucional de Iniciação Científica. Campinas: UNICAMP. 2017.

CRUZ, J.C; BARELLA, C.F; FONSECA, A. Compensating deforestation with forest surplus: key regulatory issues within Brazil's atlantic forest. Ecological Economics, v. 167. p.1-9. 2020. https://doi.org/10.10116/j.ecolecon.2019.106444

DEAN, W. A ferro e fogo: a história e a devastação da Mata Atlântica brasileira. 1. ed. São Paulo: Cia. das Letras, 2004. $484 \mathrm{p}$.

FBDS. Fundação Brasileira para o Desenvolvimento Sustentável. Mapeamento em Alta Resolução dos Biomas Brasileiros: arquivos vetoriais, metadados e metodologia. 2018. Disponível em: www.geo.fbds.org.br. Acesso em: 05 mai. 2019.

$\begin{array}{llllll}\text { Caminhos de Geografia } & \text { Uberlândia-MG } & \text { v. 21, n. } 74 & \text { Abr/2020 } & \text { p. 241-258 } & \text { Página } 256\end{array}$


FREITAS, F.C.M; SPAROVEK, G; MATSUMOTO, M.H. A adicionalidade do mecanismo de compensação de Reserva Legal na Lei 12.651/2012: uma análise da oferta e demanda de Cotas de Reserva Ambiental. In: SILVA, A.P.M.; MARQUES, H.R.; SAMBUICHI, R.H.R. (Orgs.) Mudanças no código florestal brasileiro: desafios para a implementação da nova lei. Rio de Janeiro: Ipea, p.125-159, 2016.

FUNDAÇÃO SOS MATA ATLÂNTICA. Atlas dos remanescentes florestais da Mata Atlântica: período 2017 - 2018. São Paulo. 2018. Disponível em: www.sosma.org.br. Acesso em: 05 mai. 2019

GAVIOLI, F.R. O impacto da lei florestal brasileira na instituição de Reservas Legais no território paulista: um estudo a partir dos dados públicos do Sistema de Cadastro Ambiental Rural. Desenvolvimento e Meio Ambiente (UFPR), v. 42, p. 160-179, 2017. http://dx.doi.org/10.5380/dma.v42i0.52873

GIANNICHI, M.L; GAVISH, Y; BAKER, T.R; DALLIMER, M; ZIV, G. Scale dependency of conservation outcomes in a forest offsetting scheme. Conservation Biology, p.1-10, 2019. https://doi.org/10.1111/cobi.13362

GUIDOTTI, V; FREITAS, F.L.M; SPAROVEK, G; PINTO, L.F.G; CARVALHO, C.H.T; CERIGNONI, F. Números detalhados do Novo Código Florestal e suas implicações para os PRAs. Sustentabilidade em Debate, n. 05., IMAFLORA: Piracicaba, 2017. http://www.imaflora.org

INCRA. Instituto Nacional de Colonização e Reforma Agrária. Tabela com módulo fiscal dos municípios. Disponível em: www.incra.gov.br. Acesso em: 05 mai. 2019.

JUNDIAÍ. Lei no 3.672 de 10 de janeiro de 1991. Cria a Reserva Biológica Municipal da Serra do Japi. Diário Oficial do Município de Jundiaí, Jundiaí: 10 de janeiro 1991. Disponível em: https://jundiai.sp.gov.br/planejamento-e-meio-ambiente/wp-content/uploads/sites/15/2014/08/Lei-367291.pdf. Acesso em: 06 dez.2019.

JUNG, S; RASMUSSEN, L.V; WATKINS, C; NEWTON, P; AGRAWAL, A. Brazil's national environmental registry of rural properties; implications for livelihoods. Ecological Economics, v. 136, p. 53-61, 2017. https://doi.org/10.1016/j.ecolecon.2017.02.004

LAUDARES, S.S.A; SILVA, K.G; BORGES, L.A.C. Cadastro Ambiental Rural: uma análise da nova ferramenta para regularização ambiental no Brasil. Desenvolvimento e Meio Ambiente (UFPR), v. 31, p. 111-122, 2014. https://doi.org/10.5380/dma.v31i0.33743

LAUDARES, S.S.A; BORGES, L.A.C; REZENDE, J.L.P; BICALHO, M.L; BARROS, V.C.C. New contours of the native vegetation protection law of 2012. Floresta e Ambiente, v.26, n.4, p.1-13, 2019. https://doi.org/10.1590/2179-8087.061216

MACHADO, L.A. O cadastro ambiental rural e as cotas de reserva ambiental no novo código florestal: uma análise de aspecto legais essenciais para sua implementação. In: SILVA, A.P.M.; MARQUES, H.R.; SAMBUICHI, R.H.R. (Orgs.) Mudanças no código florestal brasileiro: desafios para a implementação da nova lei. Rio de Janeiro: Ipea, p.45-79, 2016.

MARIGA, J.T; RUSCHEINSKY, A. Políticas públicas decorrentes da mudança no Código Florestal. Revista Interações, v. 18, n. 3, p.83-96. 2017. https://doi.org/10.20435/inter.v18i3.1441

MILARÉ, E.; MACHADO, P.A.L. (Orgs.). Novo Código Florestal: comentários à Lei 12.651, de 25 de maio de 2012 e à Medida Provisória 571, de 25 de maio de 2012. 1a ed. São Paulo: Revista dos Tribunais, 2012.

MYERS, N; MITTERMEIER, R.A; MITTERMEIER, C.G; FONSECA, G..A.B; KENT, J. Biodiversity hotspots for conservation priorities. Nature, v. 403, n. 24, p.853-858. 2000. https://www.nature.com/articles/35002501.pdf. https://doi.org/10.1038/35002501

OTANI, M.N; VERDI, A.R; FREDO, C.E; RAMOS, R.C. Circuito das Frutas paulista: caracterização socioeconômica. Revista Informações Econômicas, Instituto de Economia Agrícola. V.42, n.3, p.50-64. 2012.

PEREIRA, A.C.D. Novo código florestal brasileiro e as cotas de reserva ambiental sob a ótica da pequena propriedade rural: um estudo de caso. Dissertação (Mestrado em Desenvolvimento Regional) Universidade Tecnológica Federal do Paraná, Pato Branco, 2017, 142p.

PEREIRA, E.C MOLINA, S. A territorialidade no Circuito das Frutas: o conceito de territorialidade como ferramenta para implementar as políticas de desenvolvimento econômico do Circuito das Frutas. Estudos Rurais II. v.7, n.29, p.189-203. 2007. 
QUEIROGA, J.L; SILVA, I.D.S; FAGUNDES, G.G; CARVALHO, J..C; URCHEI, M.A; ALVAREZ, I.A. Sistematização de sistemas orgânicos de produção de agricultores familiares do Circuito das Frutas, estado de São Paulo. In: VI Congresso Latinoamericano de Agroecologia, X Congresso Brasileiro de Agroecologia, V Seminário de Agroecologia do Distrito Federal. Cadernos de Agroecologia, v. 13, n.1. 2018.

REED, J; VIANEN, J.V; FOLI, S; CLENDENNING, J; YANG, K.; MACDONALD, M; PETROKOFSKY, G; PADOCH, C; SUNDERLAND, T. Trees for life: the ecosystem service contribution of trees to food production and livelihoods in the tropics. Forest Policy and Economics, v.84, p.62-71, 2017. https://doi.org/10.1016/j.forpol.2017.01.012

REZENDE, C.L; SCARANO, F.R; ASSAD, E.D; JOLY, C.A; METZGER, J.P; STRASSBURG, B.B.N; TABARELLI, M; FONSECA, G.A; MITTERMEIER, R.A. From hotspot do hopespot: An opportunity for the Brazilian Atlantic Forest. Perspectives in Ecology and Conservation, v.16, p.208-214. 2018. https://doi.org/10.1016/j.pecon.2018.10.002

SANTIAGO, T.M.O; REZENDE, J.L.P; BORGES, L.A.C. The legal reserve: historical basis for the understanding and analysis of this instrument. Ciência Rural, v. 47, n.2 p. 2-9, 2017. Doi: 10.1590/01038478 cr20141349.

SÃO PAULO. Decreto Estadual n 43.284 de 03 de julho de 1998. Regulamenta as Leis nํㅗ 4023 de 22/05/1984 e 4095 de 12/06/1984, que declaram áreas de proteção ambiental as regiões urbanas e rurais dos municípios de Cabreúva e Jundiaí, respectivamente, e dá providências correlatas. Diário Oficial do Estado de São Paulo, São Paulo: 04 de julho 1998. Disponível em: https://www.al.sp.gov.br/norma/6770. Acesso em: 06 dez.2019

SÃO PAULO. Lei no 12.290 de 02 de março de 2006. Altera os limites da Área de Proteção Ambiental de Jundiaí, na forma que especifica. Diário Oficial do Estado de São Paulo: 03 de março 2006a. Disponível em: https://www.al.sp.gov.br/norma/61533. Acesso em: 06 dez.2019.

SÃO PAULO. Lei no 12.289 de 02 de março de 2006. Altera os limites da Área de Proteção Ambiental de Cabreúva, na forma que especifica. Diário Oficial do Estado de São Paulo: 03 de março $2006 \mathrm{~b}$. Disponível em: https://www.al.sp.gov.br/norma/61532. Acesso em: 06 dez.2019.

SCHMIDT, K; MARTÍN-LÓPEZ, B; PHILLIPS, P.M; JULIUS, E; MAKAN, N; WALZ, A. Key landscape features in the provision of ecosystem services: insights for management. Land Use Policy, v. 82, p.353366. 2019. https://doi.org/10.1016/j.landusepol.2018.12.022

SICAR. Sistema Nacional de Cadastro Ambiental Rural. Serviço Florestal Brasileiro, 2019. Disponível em: www.car.gov.br. Acesso em: 05 mai. 2019.

SOARES, G.R; BORGES, L.A.C; FILHO, L.O.M. Flexibilizações do novo código florestal brasileiro em imóveis rurais as margens do Rio Grande. Revista em Agronegócio e Meio Ambiente (RAMA), v. 12, n.2, p.557-553, 2019. https://doi.org/10.17765/2176-9168.2019v12n2p557-573

SOARES-FILHO, B; RAJÃO, R; MACEDO, M; CARNEIRO, A; COSTA, W; COE, M; RODRIGUES, H; ALENCAR, A. Cracking Brazil's Forest Code. Science. vol. 344, p.363-364. 2014. https://doi.org/10.1126/science.1246663

SOUZA-ESQUERDO, V.F; BERGAMASCO, S.M.P.P. Análise sobre o acesso aos Programas de Políticas Públicas da Agricultura Familiar nos municípios do Circuito das Frutas (SP). Revista de Economia e Sociologia Rural, v.52. p.205-222, 2014. WOLLMANN, L.M; BASTOS, L.C. Novo código florestal e reserva legal em propriedades rurais do município de Porto Alegre/RS. Ciência Rural, v.45, n.3, p.412417, 2015. https://doi.org/10.1590/0103-8478cr20140432

Recebido em: 30/08/2019

Aceito para publicação em: 14/01/2020 